\title{
Experimental and Numerical Analysis of Diesel Fuel Atomization Characteristics of a Piezo Injection System
}

\author{
H.K. Suh ${ }^{1}$ and C.S. Lee ${ }^{2 *}$ \\ 1 Graduate School of Hanyang University, Department of Mechanical Engineering, Hanyang University, \\ 17 Haengdang-dong, Sungdong-gu, Seoul, 133-791 - Korea \\ 2 Department of Mechanical Engineering, Hanyang Univeristy, 17 Haengdang-dong, Sungdong-gu, Seoul, $133-791$ - Korea \\ e-mail: hksuh@hanyang.ac.kr - cslee@hanyang.ac.kr \\ * Corresponding author
}

\begin{abstract}
Résumé - L'analyse expérimentale et numérique des caractéristiques d'atomisation du carburant diesel dans un système de piézo-injection - L'objectif de cette étude était de déterminer les caractéristiques d'une pulvérisation de carburant injecté par un système de piezo-injection, et de comparer les résultats expérimentaux et numériques avec ceux obtenus avec un système d'injection à solénoïde. Pour examiner l'effet d'un système d'injection de carburant et de l'angle de pulvérisation sur les performances de pulvérisation tels que le profil d'injection, l'évolution du jet et les caractéristiques d'atomisation, différents systèmes avec contrôle par la buse d'injection avec le même nez d'injection ont été utilisés. Pour l'approche numérique, un modèle modifié d'écoulement en tuyère et un modèle de désagrégation ont été appliqués à la simulation de l'atomisation de jet en utilisant les mêmes conditions dans le calcul que lors de l'expérimentation. On a trouvé que le système de piezo-injection atteint rapidement le taux maximum d'injection et a des profils d'injection uniformes. La pénétration du jet expérimentée et calculée des deux systèmes d'injection a montré des résultats similaires avec l'augmentation de la pression ambiante. Les caractéristiques de l'atomisation microscopique et les performances remarquables du système piezo-injection apportent une grande amélioration de la pulvérisation du jet.
\end{abstract}

\footnotetext{
Abstract - Experimental and Numerical Analysis of Diesel Fuel Atomization Characteristics of a Piezo Injection System - The purpose of this study was to determine the characteristics of the fuel spray, injected through a piezo injection system, and to compare the experimental and numerical results to that obtained using a solenoid injection system. In order to investigate the effect of a fuel injection system and spray angle on fuel spray performance such as fuel injection profile, evolution of fuel spray, and atomization characteristics, different nozzle-driven systems with the same nozzle specifications were used. For the numerical approaches, a modified nozzle flow model and a breakup model was applied to the simulation of spray atomization using the same calculated conditions as the experiments. It was found that the piezo injection system rapidly reaches the peak injection rate and had uniform injection profiles. The experimental and calculated spray tip penetration of both injection systems showed good agreement as the ambient pressure increased. The microscopic atomization characteristics of the high-pressure piezo injection system indicated that the outstanding injection performance of the piezo injector promoted droplet atomization.
} 


\section{INTRODUCTION}

Small, high-speed, direct injection diesel engines require a high-performance fuel injection system, featuring rapid injection sequences, low weight, and a small installation volume so that lower fuel consumption can be achieved and stricter emission limits met. In pursuit of this goal, the common-rail injection system with high-pressure injection of fuel has received a lot of attention because it can enhance the fuel atomization, has short injection duration, and controls the injection timing and injected fuel quantity at engine operating conditions. Therefore, many studies have been conducted to increase the engine performance and reduce the pollutant emissions in a common-rail engine system (Tanaka et al., 2002; Helmantel et al., 2005; Arcoumanis, 2000).

Ganser (1998) investigates the effect of injection rate parameters on the needle opening speed, valve lift and injection rate of common rail injection system in a diesel engine. He shows the characteristics of two step lift of solenoid valve and control factors of the injection rate in a common rail injection system. Gupta et al. (2000) reports the effect of various injection parameters such as ambient density and injection pressure on macro characteristics of diesel spray by common rail injection system. Their results show that a statistical correlation fit for measured penetration of the spray is excellent agreement with those obtained using a non-dimensional analysis. Additionally, Kim and Lee (2007) investigate that a narrow spray angle injector and dual injection system improve the reduction of exhaust emissions and effect of fuel injection timing are investigated by using dual injection strategy. Lai et al. (1998) empirically studied the effect of injector geometry features on fuel spray characteristics. Their results show that the spray behavior near the nozzle tip is highly transient and greatly influenced by nozzle geometry. In order to reduce the exhaust emissions, Timothy et al. (2005) studied the lean and rich, premixed charge compression ignition engine and reported that it can reduce $\mathrm{NO}_{\mathrm{x}}$ by $97 \%$ and P.M. by $79 \%$.

However, the common-rail injection system has limitations because the solenoid injection system that is used for fuel injection in a common-rail system is restricted in its application for more precisely injected fuel control and better atomization performance. Recently, the piezo injection system that uses the piezo stack for a nozzle-driven start has replaced the solenoid injection system. The piezo injection system can offer a shorter period of time needed to open the needle for the fuel injection and a higher opening force, as compared to the solenoid system. Koyanagi et al. (1999) conducted experiments on the combustion characteristics of the optical engine with piezo and solenoid injection systems. They report that the piezo injection system can be used in applications of widely used diesel engine combustion, as opposed to a solenoid injection system. Tayler and Washington (2003) report that the energy required for a piezo injection system is different from that required for a conventional solenoid injection system and that the former can successfully deliver the required force and stroke of an engine. Fettes and Leipertz (2001) characterize the atomization characteristics and combustion performances of a diesel engine with a piezo injection system. They also analyze the effect of nozzle type on spray characteristics, using a valve-covered orifice (VCO) and sac-volume nozzles. They report that VCO nozzles cause large spray cone angles and improve the air entrainment into the spray, which can promote vaporization.

As illustrated above, the spray characteristics of a piezo injection system might be different from those of the solenoid driven injection system, because the injection velocity and formation of spray in the internal structure must be different. Therefore, the investigation of spray pattern and atomization characteristics of the piezo injection system is very important for the improvement of fuel combustion and reduction of exhaust emissions from the engine. There have been many studies on the spray characteristics of a piezo injection system, but the effect of the injector-driven system on atomization characteristics has not been fully examined. In particular, experiments using the piezo and solenoid injection systems that have the same nozzle specifications are required to determine the effect of the injector-driven system on spray characteristics.

The aim of this study was to explore the effect of the nozzle-driven system on the characteristics of fuel spray, including the injection rate, spray tip development, and Sauter mean diameter (SMD) distribution under various injection conditions, both experimentally and theoretically. The numerical study was performed using the KIVA code with cavitation considered in the injection model, and the droplet breakup was measured with the KH-DDB (Kelvin-Helmholtz instability/droplet deformation and breakup) model suggested by Park and Lee (2003) under the same conditions as the experiments.

\section{EXPERIMENTAL APPARATUS AND PROCEDURES}

\subsection{Experimental Apparatus}

In this study, the effect of an injector driven system on the fuel injection rate, macroscopic and atomization spray characteristics were analyzed by testing the piezo and solenoid injection systems. An injector nozzle with a different fuel injection angle was also used to explore the effect of nozzle geometry on spray characteristics. The detail schematics of test nozzles are illustrated in Figure 1. The injectors used in this study had five nozzle holes with a hole diameter of $0.168 \mathrm{~mm}$ and a hole depth of $0.9 \mathrm{~mm}$. The half spray angle of test nozzles is 50 and $75^{\circ}$. 

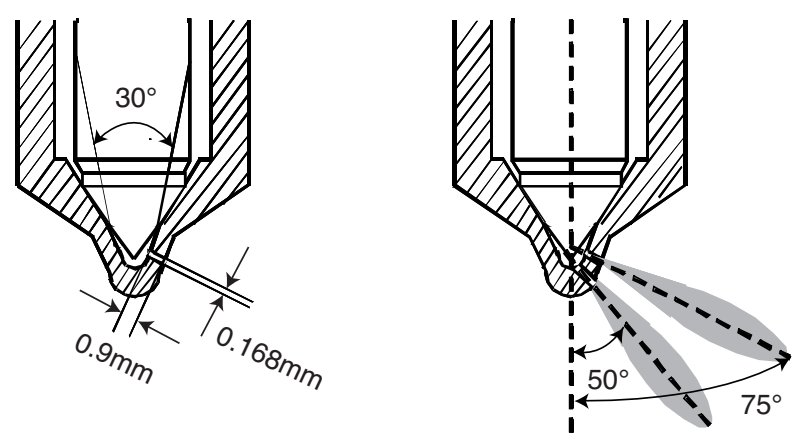

Figure 1

Test nozzle specifications.

The injection rate characteristics of fuel spray such as injection delay and peak injection rate is important because it can be used for nozzle design and provides the input data to the numerical analysis. In this study, the widely applied injection rate measuring system applied Bosch (1966) method was used to obtain the time resolved injection profiles of the two injection system. The pressure in the tube was kept constant at $3 \mathrm{MPa}$ during the fuel injection. A piezotype pressure sensor was utilized in the injection chamber to measure the pressure of the tube and one thousand continuous injections were averaged for each test case.

Figure 2 shows the high-pressure injection and spray visualization systems for the investigation of the fuel spray evolution characteristics. The fuel injection system consisted of two high-pressure fuel pumps operated by compressed air, a pressure regulator, and a common-rail. The fuel was compressed by a high-pressure fuel pump (Haskel, HSF-300) and accumulated in a common-rail. The spray visualization system was composed of an Ar-ion laser, cylindrical lenses and mirrors, a digital time delay/pulse generator (Berkeley Nucleonics Corp, Model 555), an intensified charged coupled device (ICCD) camera (Cooke cooperation, Dicam Pro), and a PC installed image grabber. Macroscopic spray characteristics, such as spray tip penetration and overall behavior, could be directly obtained from the spray frozen image of bottom view by using the spray visualization system. The solenoid and piezo injection systems were controlled by an injector driver (TEMS Co., TDA-3200H) and a prototype injector driver (Piezomechanik, HVP-Diesel Ci 200/20-4), respectively.

The PDPA system, also illustrated in Figure 2, was used to characterize the fuel sprays in terms of Sauter mean diameter (SMD) and velocity distributions. As shown in this figure, spray visualization and phase Doppler particle analyzer (PDPA) system were composed of a light source, a transmitter, a receiver and a signal analyzer. The detail specifications of spray visualization and the PDPA system are shown in Table 1.

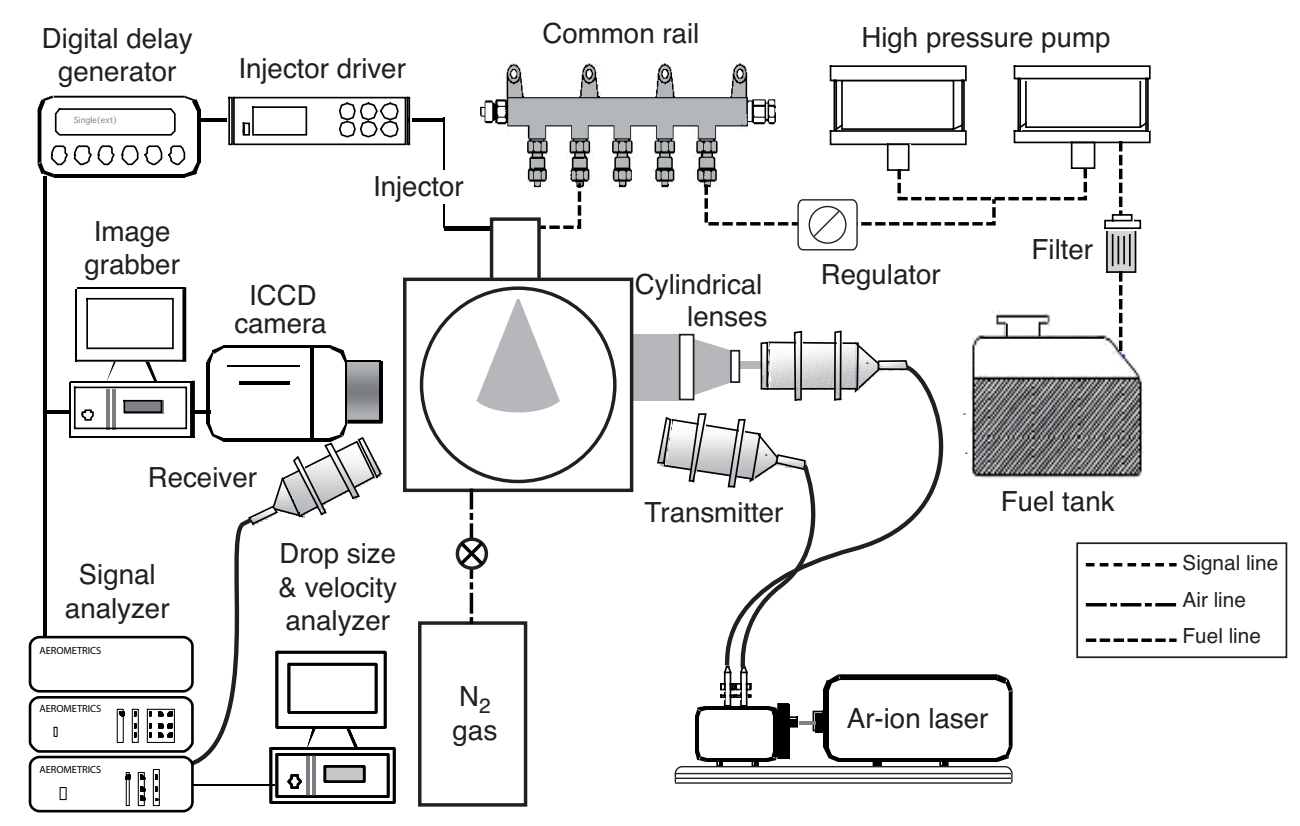

Figure 2

Spray visualization and PDPA measuring system. 
TABLE 1

Specifications of spray visualization and droplet analysis system

\begin{tabular}{c|c|l}
\hline \multirow{2}{*}{$\begin{array}{c}\text { Spray } \\
\text { visualization } \\
\text { system }\end{array}$} & Light source & Ar-ion laser \\
\cline { 2 - 3 } & Wave length & $514.5 \mathrm{~nm}$ \\
\cline { 2 - 3 } & Laser power & $1.2 \mathrm{~W}$ \\
\hline \multirow{2}{*}{$\begin{array}{c}\text { ICCD } \\
\text { camera }\end{array}$} & Pixel size & $6.7 \mu \mathrm{m} \times 6.7 \mu \mathrm{m}$ \\
\cline { 2 - 3 } & Resolution & $1280(\mathrm{H}) \times 1024(\mathrm{~V})$ \\
\hline \multirow{3}{*}{$\begin{array}{c}\text { PDPA } \\
\text { system }\end{array}$} & Wave length & $514.5 \mathrm{~nm}, 488 \mathrm{~nm}$ \\
\cline { 2 - 3 } & Focal length & $500 \mathrm{~mm}$ for transmitter and receiver \\
\cline { 2 - 3 } & Collection angle & $30^{\circ}$ \\
\hline
\end{tabular}

\subsection{Experimental Procedures}

In this investigation, by analyzing the experimental results, spray characteristics such as spray structure, SMD distributions and microscopic characteristics were studied. These results were also used for predicting the accuracy of the numerical calculations obtained from the KIVA code. Table 2 lists the experimental conditions for the study of the effect of an injector driven system on the fuel atomization characteristics. The injection profiles were obtained at different energizing durations from $0.3 \mathrm{~ms}$ to $0.7 \mathrm{~ms}$. In contrast, the energizing duration for the spray development visualization was fixed at $0.5 \mathrm{~ms}$ because that duration showed a characterized performance compared with piezo and solenoid injection systems.

TABLE 2

Experimental conditions

\begin{tabular}{l|l}
\hline Injector type & Piezo-driven and Solenoid-driven \\
\hline Injection pressure $\left(P_{\mathrm{inj}}\right)$ & $80 \mathrm{MPa}$ \\
\hline Ambient pressure $\left(P_{\mathrm{amb}}\right)$ & $\begin{array}{l}0.1 \mathrm{MPa}, 3 \mathrm{MPa} \text { (spray visualization) } \\
0.1 \mathrm{MPa}(\mathrm{PDPA})\end{array}$ \\
\hline Ambient temperature $\left(T_{\mathrm{amb}}\right)$ & $293 \mathrm{~K}$ \\
\hline Energizing duration $\left(t_{\mathrm{eng}}\right)$ & $\begin{array}{l}0.3 \sim 0.7 \mathrm{~ms} \text { (injection rate measuring) } \\
0.5 \mathrm{~ms} \text { (spray visualization, PDPA) }\end{array}$ \\
\hline
\end{tabular}

In order to determine the spray tip penetration and spray cone angle, discernment had to be made between spray images and the image background. In this study, the bright distributions of the original image were analyzed and the optimal threshold level should be determined. By determining the optimal threshold level, the spray tip penetration and spray cone angle could be obtained more accurately. The definition of spray tip penetration is the maximum distance that spray can reach from the nozzle tip, and the spray cone angle was defined as the two straight lines from the nozzle tip formed by the spray outer, as can be seen in Figure 3. Figure 3 also shows the measurement points and the coordination systems of the SMD and velocity measurements. For each measurement point, approximately 30000 droplets were collected and averaged to obtain the SMD and mean velocity of the point. The representative SMD of a spray droplet at a specific time was determined by averaging the captured droplets at all measurement points. The overall SMD and velocity that implied the 30000 measured droplets at each measurement locations is greatly influenced on the droplets at the specific time interval. This will bias the results in the collection times at those spatial locations might be dramatically different. Based on these reason, the overall SMD and axial mean velocity at a specific time $(t)$ can be determined as followed,

$$
\begin{gathered}
\text { Overall SMD }=\left(\sum_{t}^{t+\Delta t} \sum_{i=1}^{n} D_{i}^{3}\right) /\left(\sum_{t}^{t+\Delta t} \sum_{i=1}^{n} D_{i}^{2}\right) \\
\text { Overall velocity }=\frac{1}{n}\left(\sum_{t}^{t+\Delta t} \sum_{i=1}^{n} V_{i}\right)
\end{gathered}
$$

where, $D$ is the diameter of droplets, $V$ and $n$ indicate the velocity and number of droplets, respectively.

For improving the reliability of the PDPA experimental results, the data acquisition rate and the validation percent of the droplet measuring should be investigated. The measurement of droplet size using PDPA system may be caused the problems such as multiple droplets in the measuring volume can give rise to low data acquisition rates and increased measurement uncertainty. In this work, the data acquisition rate of the droplet size is increased with the increase in axial distance from the nozzle tip, and validation percent of velocity

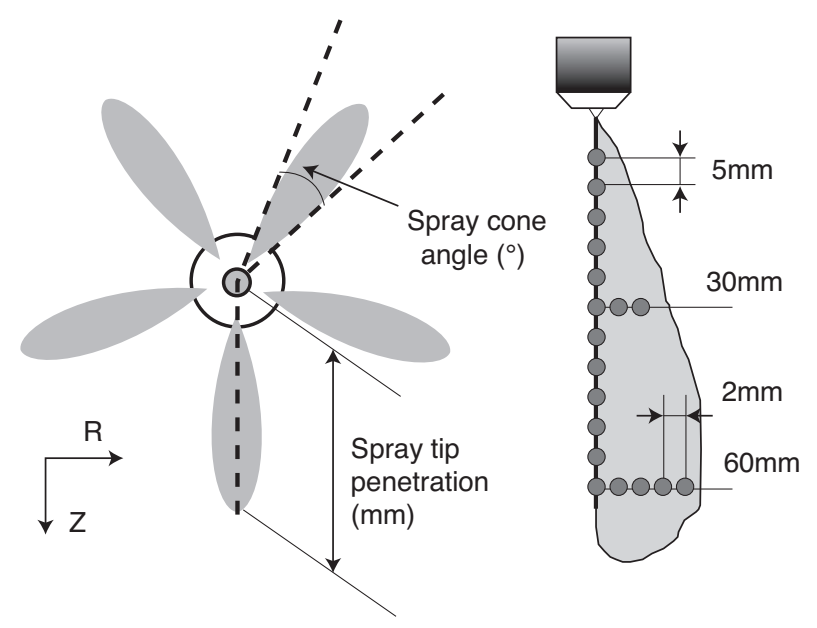

Figure 3

Definitions of spray characteristics and measuring points. 
measurement was over than $95 \%$ in all measuring points. Base on these results, it might be assumed that the PDPA measuring results could be reliable in this study. The PDPA measurement was conducted based on the $0.5 \mathrm{mV}$ of threshold voltage and $65 \%$ of signal-to-noise ratio. By adjusting these conditions, the data rate or the resulting accuracy could be improved. In this study, the velocity measurement range of the PDPA system was expanded from $-292 \mathrm{~m} / \mathrm{s}$ to $292 \mathrm{~m} / \mathrm{s}$ by using the expander for the beam transmitter. The cut-off range of the droplet diameter was from $2 \mu \mathrm{m}$ to $100 \mu \mathrm{m}$. By applying these conditions, the measurement of SMD and velocity were set to optimum value for the high speed diesel fuel spray.

\section{NUMERICAL PROCEDURES}

The CFD calculations are important for the improvement of engine performance and should be compared with experimental results. Therefore, in this study, numerical approaches based on the KIVA code were performed under the same conditions for the spray visualization experiments. With consideration of the nozzle cavitation effect, the initial droplet size and effective injection velocity needed for input into the KIVA code were obtained from the nozzle flow model suggested by Sarre et al. (1999). The KH-DDB model by Park and Lee (2003) was used to analyze the droplet breakup. From these analyses, the spray tip penetration, overall SMD and mean velocity were obtained and compared with experimental results.

\subsection{Nozzle Flow Model of Injection Nozzle}

Under a high pressure injection system, such as common-rail, nozzle cavitation flow may occur and the cavitation effect must be considered in determining injection velocity and initial droplet size. In this study, the nozzle flow model suggested by Sarre et al. (1999) was applied when the pressure at the nozzle vena contracta was lower than the vapor pressure. In order to obtain the effective initial velocity $\left(u_{e f f}\right)$ and droplet diameter $\left(d_{e f f}\right)$, the injection mass flow rate, the ambient pressure, the fuel physical property, the nozzle hole diameter $(D), L / D$ ratio and $R / D$ ratio had to be determined as a input data. To calculate the effective injection velocity $\left(u_{e f f}\right)$ and initial diameter $\left(d_{e f f}\right)$, the mean velocity $\left(u_{m}\right)$ was obtained from the mass flow rate, liquid density, and nozzle diameter:

$$
\dot{m}=\rho_{l} C_{d} A_{n} u_{m}
$$

The inlet pressure $\left(P_{i}\right)$ could be estimated under the assumption of a turbulent flow as:

$$
P_{i}=P_{b}+\frac{1}{2} \rho_{l} u_{m}^{2}
$$

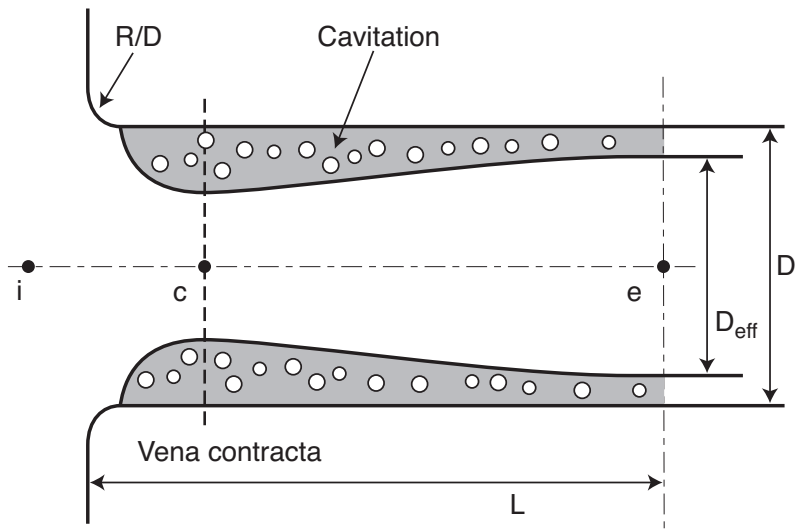

Figure 4

Liquid and vapor separation in a fuel nozzle.

where $\rho_{l}$ is the fuel density, $C_{d}$ is discharge coefficient determined by dividing the actual mass flow by the ideal mass flow, and $P_{b}$ is the discharge back pressure at the point $e$ in Figure 4 . The discharge coefficient $\left(C_{d}\right)$ is given by:

$$
C_{d}=\frac{\dot{m}}{\sqrt{2 \rho_{l} \Delta P}}
$$

The pressure at contraction zone, $c$, was assumed to the vapor pressure of fuel, therefore, this zone exist the fuel vapor and liquid phase. The mass flow of at point $c$ was given by:

$$
\dot{m}=\rho_{l} C_{c} A_{c} u_{c}
$$

where $u_{c}$ was the velocity at concentration and $C_{c}$ was the ratio of concentration area and to the nozzle area. Using the Bernoulli's equation between the inlet $i$ and contraction point $c$, the inlet pressure $P_{i}$ is given by:

$$
P_{i}=P_{v}+\frac{1}{2} \rho_{l} u_{c}^{2}
$$

Combining the Bernoulli's equation between nozzle inlet and contraction point and the continuity equation at point $c$, $C_{d}$ was expressed as:

$$
C_{d}=C_{c} \sqrt{\frac{P_{i}-P_{v}}{P_{i}-P_{b}}}
$$

If the pressure at the vena contracta $\left(P_{c}\right)$ was lower than the vapor pressure $\left(P_{v}\right)$, it could be assumed the flow was cavitating, and the new inlet pressure and discharged coefficient were given by Equations 4 and 5 . 
The effective injection velocity $\left(u_{e f f}\right)$ and the effective initial droplet $\left(d_{e f f}\right)$ as an input data could be obtained by momentum equilibrium between the vena contracta and nozzle exit as follows :

$$
\begin{gathered}
u_{\text {eff }}=u_{c}-\frac{P_{b}-P_{c}}{\rho_{l} u_{m}} \\
\frac{A_{\text {eff }}}{A_{n}}=\frac{u_{m}}{u_{\text {eff }}} \text { and } d_{\text {eff }}=\sqrt{\frac{4 A_{\text {eff }}}{\pi}}
\end{gathered}
$$

When the flow was not cavitating, the injection velocity of fuel was set equal to the volumetric mean velocity $\left(u_{m}\right)$, and the initial droplet was equal to the nozzle diameter.

\subsection{Breakup Model}

Many studies have been performed on the spray breakup model for high-speed diesel sprays to achieve predictions that are more accurate. The wave model suggested by Reitz (1987) and DDB model proposed by Ibrahim et al. (1993) were used for the calculation of wave instability and droplet deformation. In this study, the KH-DDB model by Park and Lee (2003) was used because it shows higher prediction accuracy in the high-speed diesel spray simulation.

Comparing the numerical results to the experimental results, the numerical calculations of spray by using KIVA code were performed under non-evaporating conditions. The calculation conditions of non-evaporating conditions were set equal to those of the experiments as listed in Table 2. The effective initial diameter and droplet distributions were predicted from the nozzle flow model obtained from injection profiles. By using KIVA code, the local and overall mean values can be calculated and compared with experimental results. In this study, the local mean value indicates the average of specific measuring points regardless of time, and overall mean value means the time dependent average value of all measuring points. The injection parcels number in the KIVA code was 5000 , and the time step was at $0.01 \mathrm{~ms}$.

\section{RESULTS AND DISCUSSIONS}

In this work, the fuel spray characteristics issued from a piezo injection system were determined both experimentally and theoretically. Additionally, the spray characteristics of the piezo injection system were compared with those of the solenoid injection system.

\subsection{Comparison of Fuel Injection Characteristics}

In order to analyze the spray injection characteristics, the fuel injection profile was investigated under various experimental conditions. The injection characteristics were analyzed quantitatively in terms of the quantity of fuel injec- tion, the injection delay, and ratio of injection duration to energizing duration, as shown in Figure 5. The quantity of fuel injected per one injection was averaged based on the total fuel mass injected for 1000 injections. As shown in Figure 5a, the injection quantities of both injectors increased almost linearly as a function of energizing duration. The effect of injection type on injection quantity showed that the injected mass of piezo injectors had about a $40 \%$ larger amount of fuel injection mass than those of solenoid injectors. These trends increased with the increase of energizing duration. However, the effect of the fuel injection angle on fuel injection mass showed little difference, because the hydraulic flow rates (HFR) of both injection angle and injection system were the same. Figure $5 \mathrm{~b}$ illustrates the injection delay, which was defined as the time interval from the start of energizing to the start of injection. In this figure, it should be noted that the piezo injection system has a faster response than the solenoid injection system, and the former could be applied to the pilot injection that needs a short energizing duration to control the fuel injection. Figure $5 \mathrm{c}$ illustrates the ratio of injection and energizing durations of the piezo and solenoid injection systems. In this figure, the ratio of injection and energizing durations of the piezo injectors show an almost constant value and longer injection duration compared to the solenoid injector with an increase of energizing duration. Moreover, the injection/energizing duration ratio of solenoid injection system shows a worsen characteristics at the short $0.3 \mathrm{~ms}$ energizing duration. Therefore, it is clear that the large amount of injected fuel, short injection delay, and stabilization of injection/energizing duration of the piezo injection system provide good injection performance.

Figure 6 illustrates the injection profiles between the piezo and solenoid injection systems obtained from the injection rate measuring system. As can be seen in this figure, the injection delay of the solenoid injector was about $0.37 \mathrm{~ms}$, whereas the injection delay of the piezo injector was $0.27 \mathrm{~ms}$. From these results, the injection response of the piezo injector was faster than that of solenoid injector, as already shown in Figure $5 \mathrm{~b}$. The piezo injector rapidly reached the peak injection rate and had uniform injection profiles, with the exception of the $0.3 \mathrm{~ms}$ energizing duration. Based on this tendency, it can be seen that it took an energizing duration of about $0.4 \mathrm{~ms}$ to fully open the nozzle of the piezo injection system. In contrast, the maximum injection rate increased with energizing duration for the solenoid injection system. In the case of solenoid injector, it took more time to reach the peak injection rate than for the piezo injector. In contrast, the peak injection rates of the piezo and solenoid injection systems were similar because nozzles with the same specification were used. 


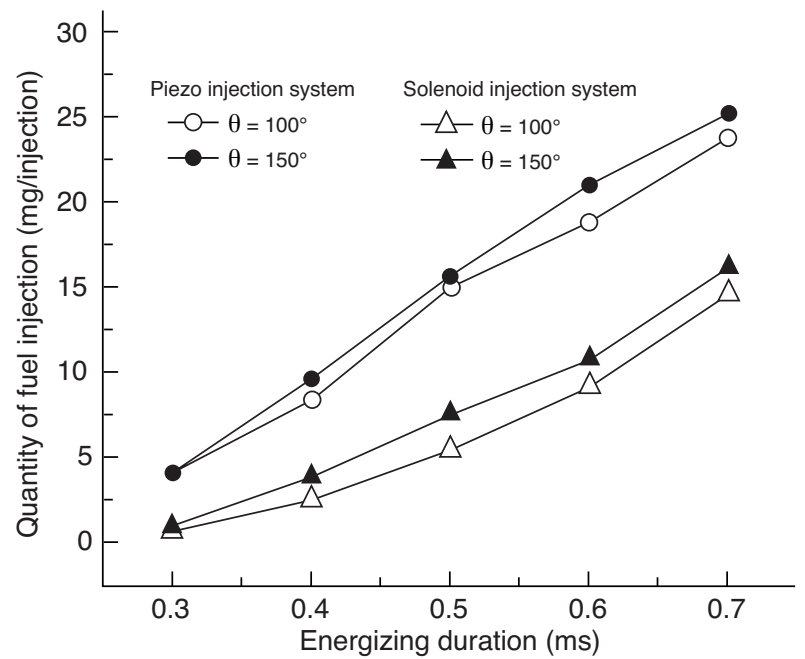

a

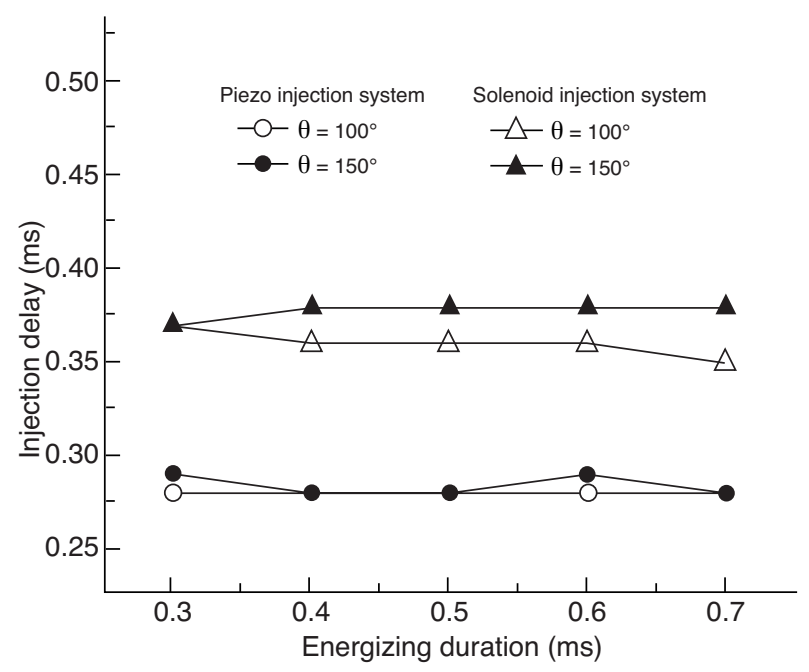

b

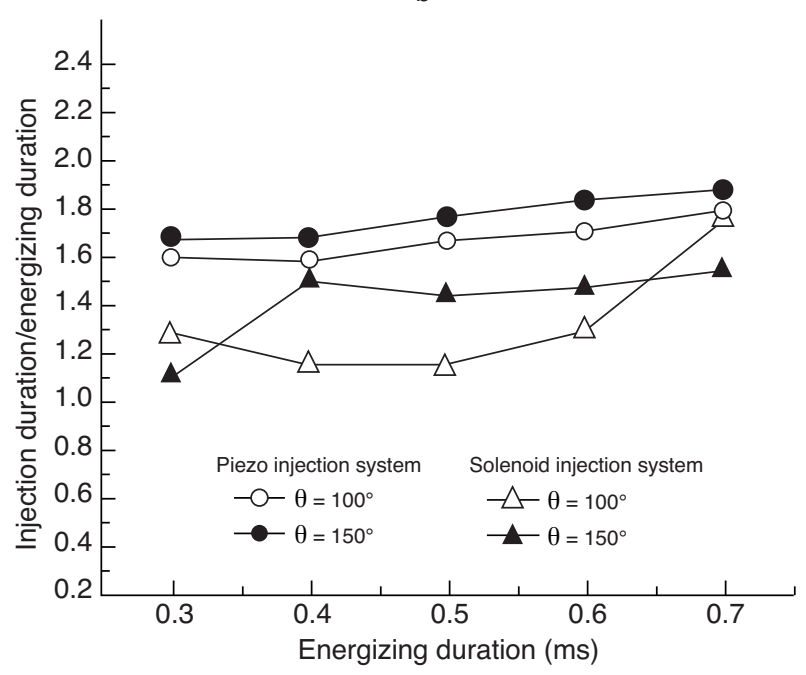

c

Figure 5

Comparisons of fuel injection characteristics $\left(P_{\text {inj }}=80 \mathrm{MPa}\right.$, $P_{\mathrm{amb}}=3 \mathrm{MPa}$ ). (a) Fuel injection quantity; (b) Injection delay; (c) Ratio of injection and energizing duration.

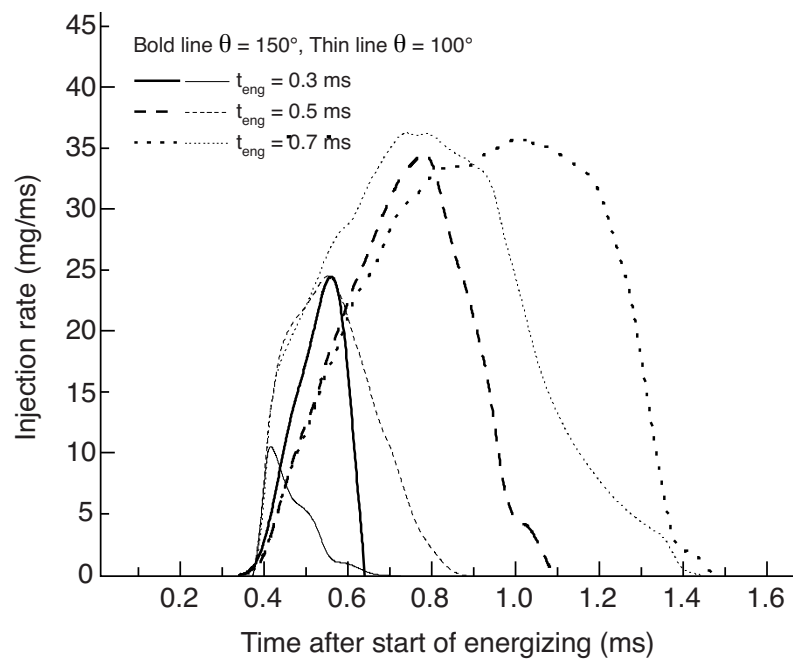

a

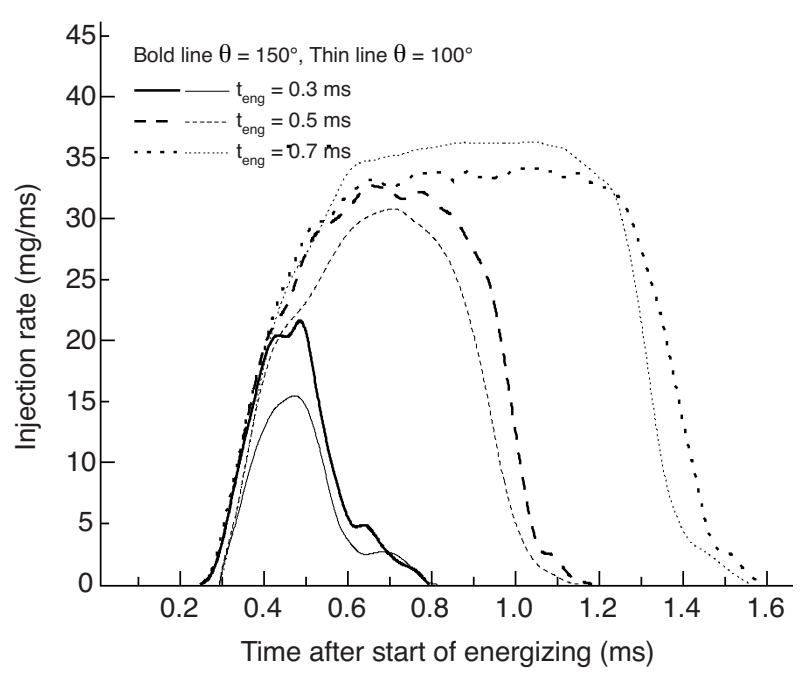

Figure 6

Effect of spray cone angle and injection type on fuel injection rate $\left(P_{\text {inj }}=80 \mathrm{MPa}, P_{\text {amb }}=3 \mathrm{MPa}\right)$. (a) Solenoid injection system; (b) Piezo injection system.

The effective injection velocities of both injectors obtained from the injection rate using the nozzle flow model are illustrated in Figure 7. Figures $7 \mathrm{a}$ and $7 \mathrm{~b}$ show $0.3 \mathrm{~ms}$ and $0.5 \mathrm{~ms}$ of energizing duration, respectively. As shown in this figure, the effective injection velocity of the piezo injectors was higher than those of the solenoid injector because the injection rate of the piezo injection system was higher as illustrated in Figures 5 and 6. It could be inferred that the higher injection velocity of piezo injectors promotes the breakup of injected droplets. The effect of injection spray angle on the effective injection velocity in the same injectors was similar and as the energizing duration increased, the effective injection velocity increased. 


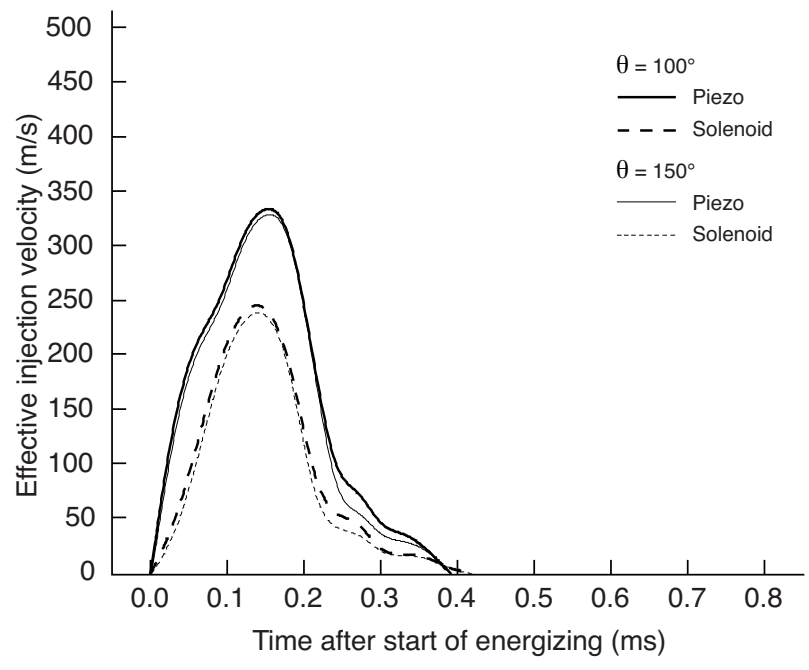

a

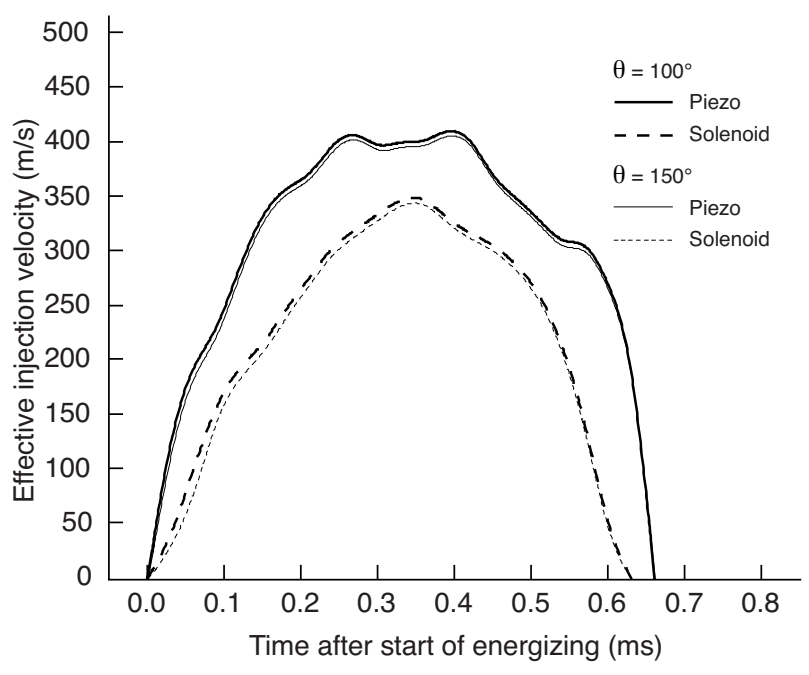

b

Figure 7

Effect of spray cone angle and injection type on effective injection velocity $\left(P_{\text {inj }}=80 \mathrm{MPa}, P_{\mathrm{amb}}=3 \mathrm{MPa}\right)$. (a) $t_{\mathrm{eng}}=0.3 \mathrm{~ms}$; (b) $t_{\mathrm{eng}}=0.5 \mathrm{~ms}$.

\subsection{Comparison of Spray Development Process}

In order to explore fuel atomization and spray characteristics, the fuel spray development process is a main factor that should be analyzed. The piezo injection system showed an outstanding performance at a short energizing duration as previously illustrated in injection profiles. The macroscopic spray development was studied at $0.5 \mathrm{~ms}$ of energizing duration since it showed characterized injection performance.

The experimental and calculated results of the spray development process of both injection angle between the piezo and solenoid injectors are illustrated in Figure 8. The spray images of this figure were obtained from the spray visualization system illustrated in Figure 2, and calculated results were estimated by using the KIVA code at $80 \mathrm{MPa}$ of injection pressure. From the experimental results, the fuel spray developments of both injectors increased in proportion to the elapsed time after start of injection. Additionally, after the start of injection, the simultaneous spray development speed of both injectors agreed well for each case. From the calculated results, it was obvious that the larger droplets distributed near the nozzle tip, and that the droplet size became smaller as they moved to the outside of the spray due to the atomization process. However, in case of 150 degree, the calculated spray results were different from the experimental images having spray development and a shape spray tip. It appears in the numerical results that the spray is no longer exiting the nozzle at $1.0 \mathrm{~ms}$, however, this is not the case shown in the experimental imaging. It could be assumed that the effective injection velocity with an injection angle of 150 degrees quickly reached the peak value and increased the injected fuel quantities, as shown in Figures 5 and 7. The calculated results for the spray SMD and velocity at 150 degrees showed a smaller overall SMD value and higher mean velocity than that at 100 degrees. These trends were

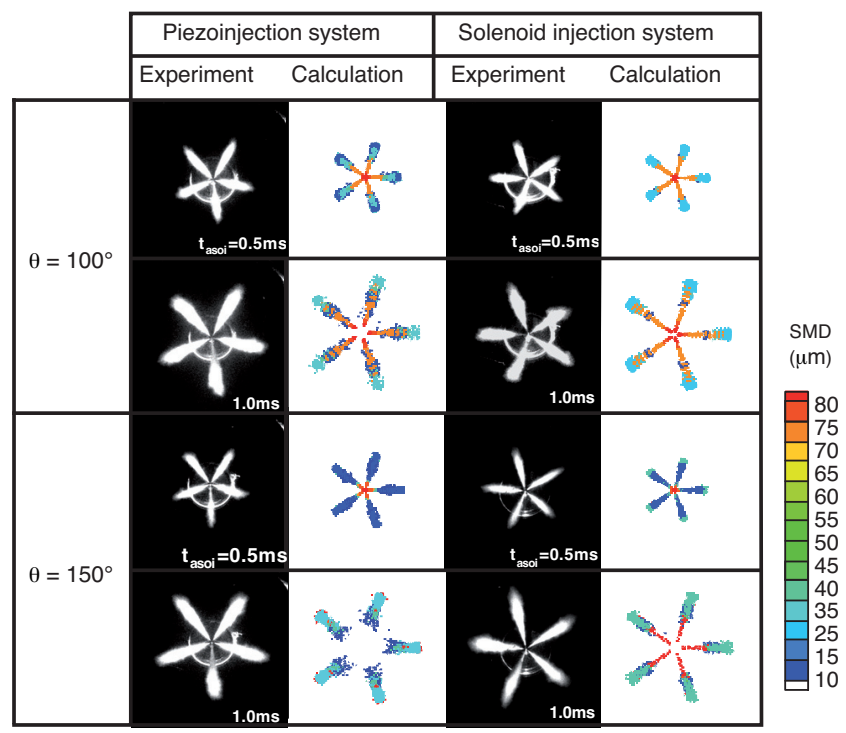

Figure 8

Experimental and calculation results of spray development process. ( $\left.P_{\text {inj }}=80 \mathrm{MPa}, P_{\text {amb }}=3 \mathrm{MPa}, t_{\text {eng }}=0.5 \mathrm{~ms}\right)$. 


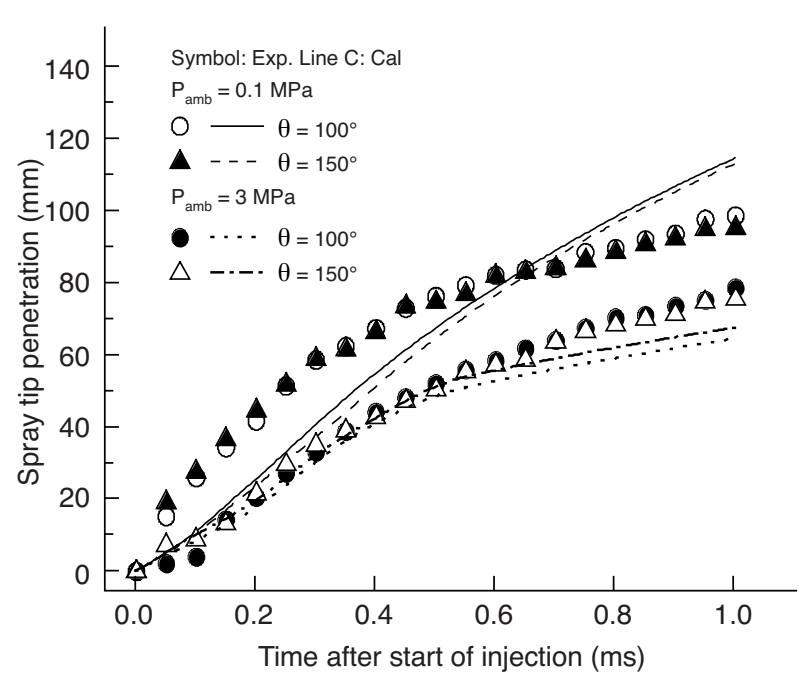

a

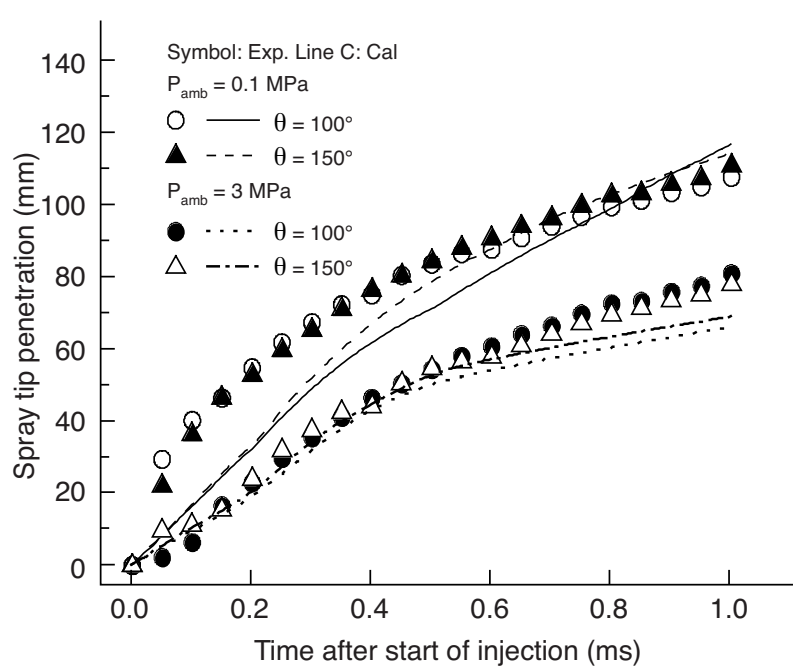

b

Figure 9

Comparison of spray tip penetrations between piezo and solenoid injection system. (a) Solenoid injection system; (b) Piezo injection system. $\left(P_{\text {inj }}=80 \mathrm{MPa}, P_{\text {amb }}=3 \mathrm{MPa}\right)$.

observed to be strong in the case of 150 degrees. This caused a higher velocity of droplets near the injector nozzle and rapid propagation at the spray tip. It was also observed that the sprays injected from the piezo injection system had spray tip penetrations similar to the solenoid injection system; however, they had a large spray cone angle. It could be assumed that the large amount of injected fuel and rapid opening of the injector needle due to the fast response of the piezo injection system caused the rapid increase of injection flow rate as shown in injection profile characteristics; thus, making a large spray cone angle.

The experimental and calculated spray tip penetrations of both injectors are described in Figure 9. In this figure, symbols and lines indicate the experiment and calculation results, respectively. In the case of experimental results, the spray tip penetration of both injectors were similar, and as the ambient pressure increases by $3 \mathrm{MPa}$, the spray tip penetration decreased because of higher ambient gas density. As indicated in Figure 9a and b, calculated spray tip penetration at $0.1 \mathrm{MPa}$ of ambient pressure show that it was underestimated before $0.6 \mathrm{~ms}$ from the start of injection. It may be guessed that the high spray momentum caused by high injection pressure induced the rapid developments of spray edges at the $0.1 \mathrm{MPa}$ of ambient pressure. On the other hands, as the ambient pressure increased to $3 \mathrm{MPa}$, the droplets at the leading edge are decelerated rapidly by the drag at the initial injection stage, it showed a good agreement. It could be concluded that the calculated spray tip penetration was strongly dependent on the ambient pressure conditions at the early stage of injection start.
In order to analyze the effect of the injection system on spray cone angle, the spray cone angle of the piezo and solenoid injection systems were compared as shown in Figure 10. The results showed that the spray cone angles of the piezo injectors were larger by about 10 degrees over those of the solenoid injectors. As mentioned previously, the large amount of injected fuel and the fast response of the nozzle opening resulted in a large spray cone angle.

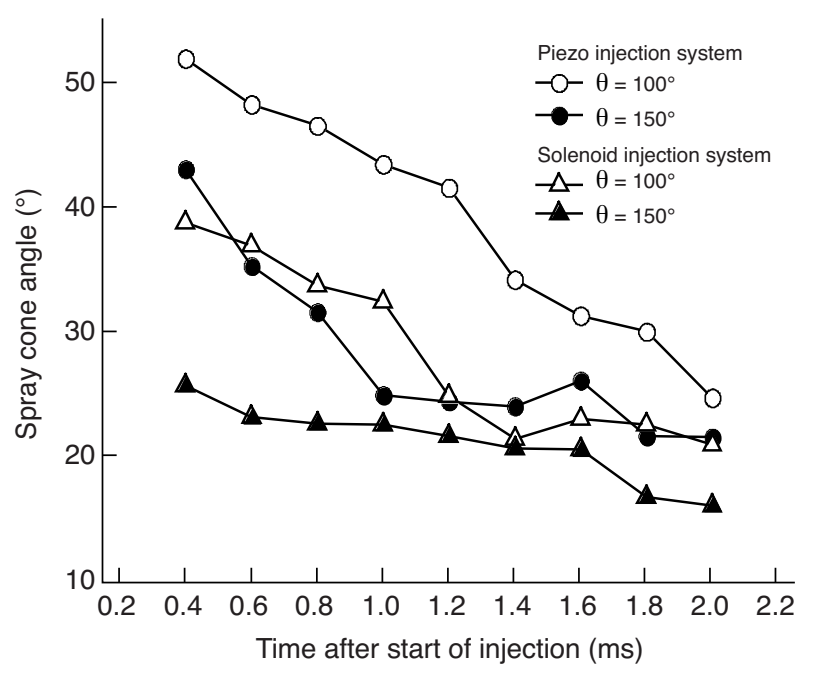

Figure 10

Experimental results of spray cone angles. $\left(P_{\text {inj }}=80 \mathrm{MPa}\right.$, $\left.P_{\text {amb }}=3 \mathrm{MPa}, t_{\text {eng }}=0.5 \mathrm{~ms}\right)$. 


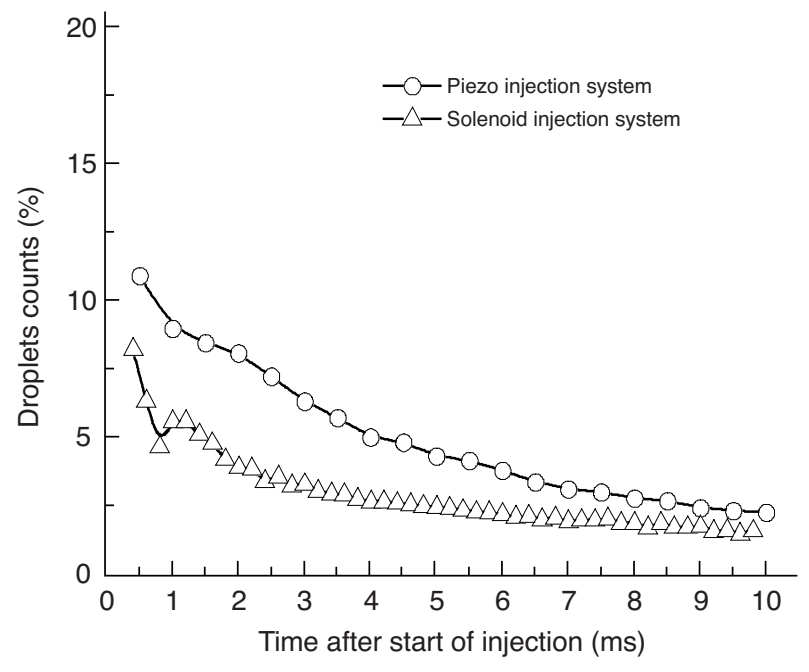

Figure 11

Number of detected droplets of both injection systems as elapsed time after start of injection. (a) $\theta=100^{\circ}$; (b) $\theta=150^{\circ}$. ( $P_{\text {ing }}=80 \mathrm{MPa}$, $\left.P_{\text {amb }}=0.1 \mathrm{MPa}, t_{\text {eng }}=0.5 \mathrm{~ms}\right)$.

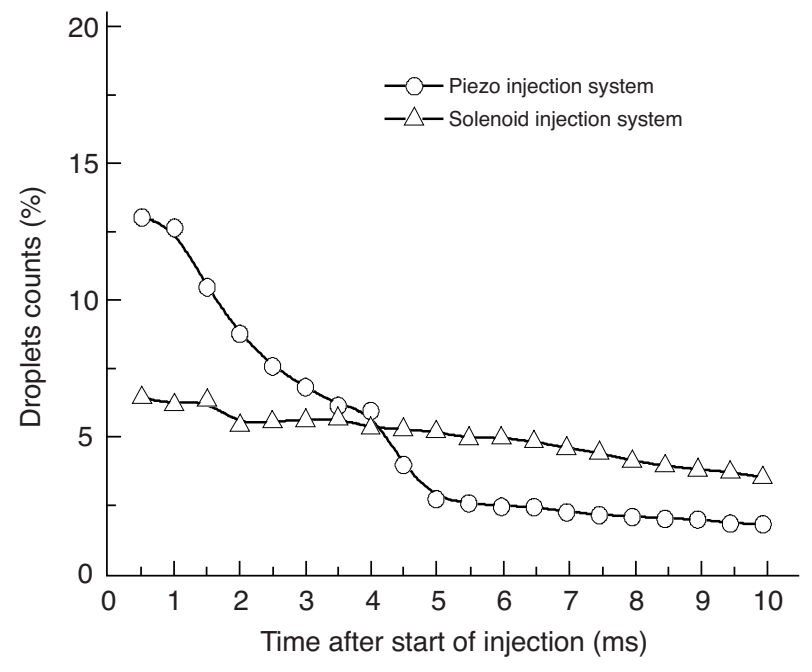

b

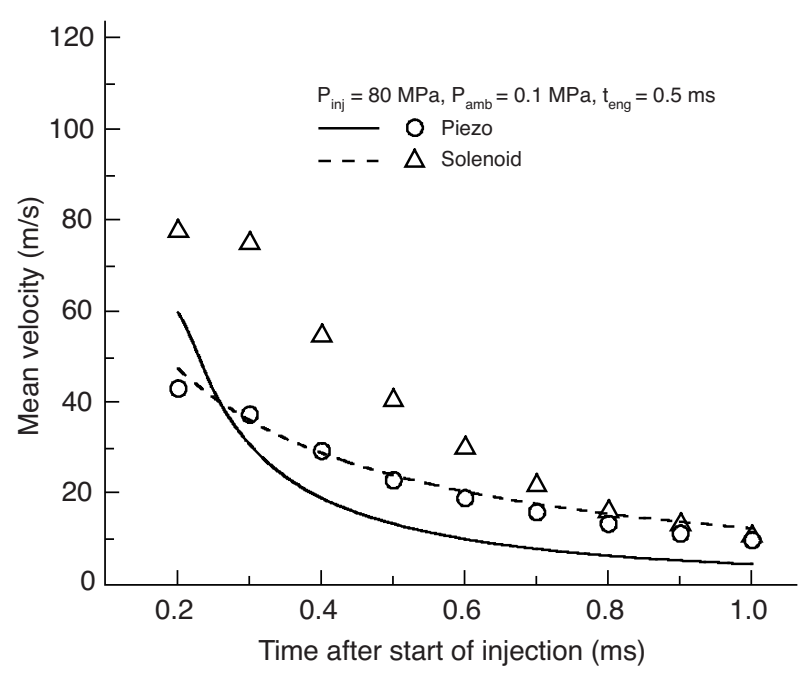

Figure 12

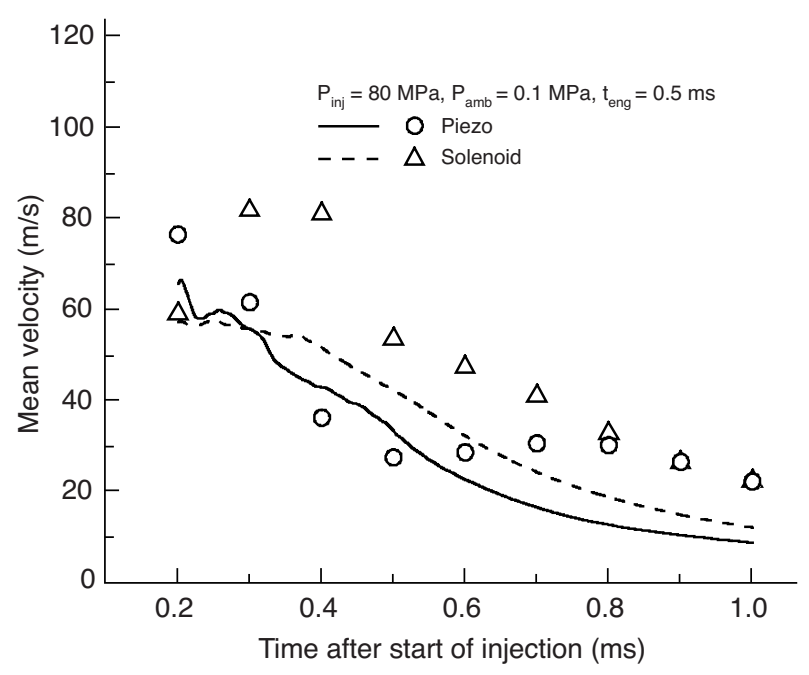

b

Droplets mean velocity of two injection system. (a) $\theta=100^{\circ}$; (b) $\theta=150^{\circ}$. $\left(P_{\text {inj }}=80 \mathrm{MPa}, P_{\mathrm{amb}}=0.1 \mathrm{MPa}, t_{\text {eng }}=0.5 \mathrm{~ms}\right)$.

\subsection{Comparison of Fuel Atomization Characteristics}

In order to investigate the microscopic atomization characteristics of the piezo and solenoid injection system, the overall SMD and mean velocity distributions were analyzed. The experimental results of SMD were determined by averaging the droplets of spray captured by the phase Doppler particle analyzer system in the measuring point at the specific time interval.
Figure 11 illustrates the droplet detection percentage of both injection systems that indicates the ratio of detected droplet number at the specific and whole injection time. Because the injected fuel quantities are not the same in this study, the detection percentage of droplets was applied. In case of 100 degree of injection angle in Figure 11a, piezo injection system detected the many droplets in the whole injection time. In case of 150 degree of injection angle as shown in Figure 11b, the many droplets of piezo injection 


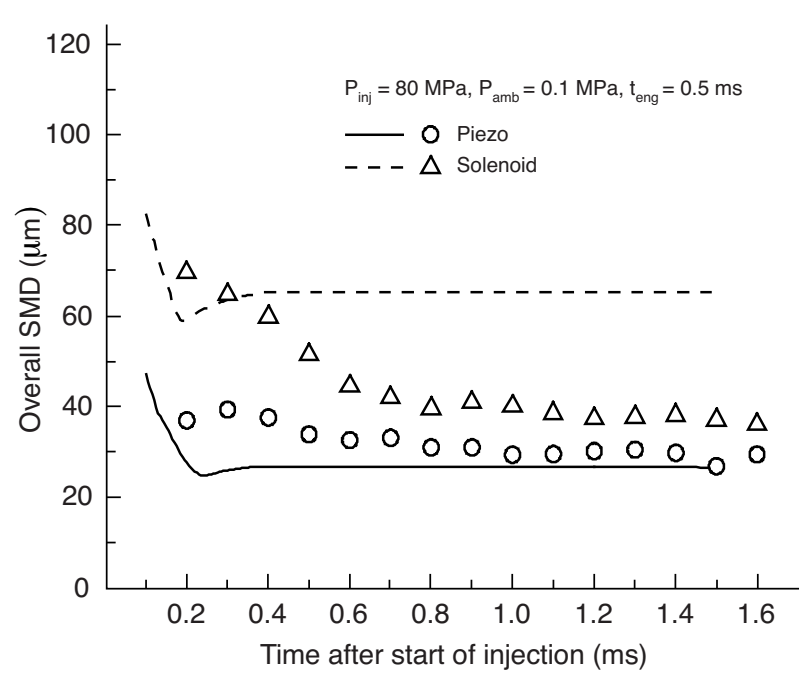

a

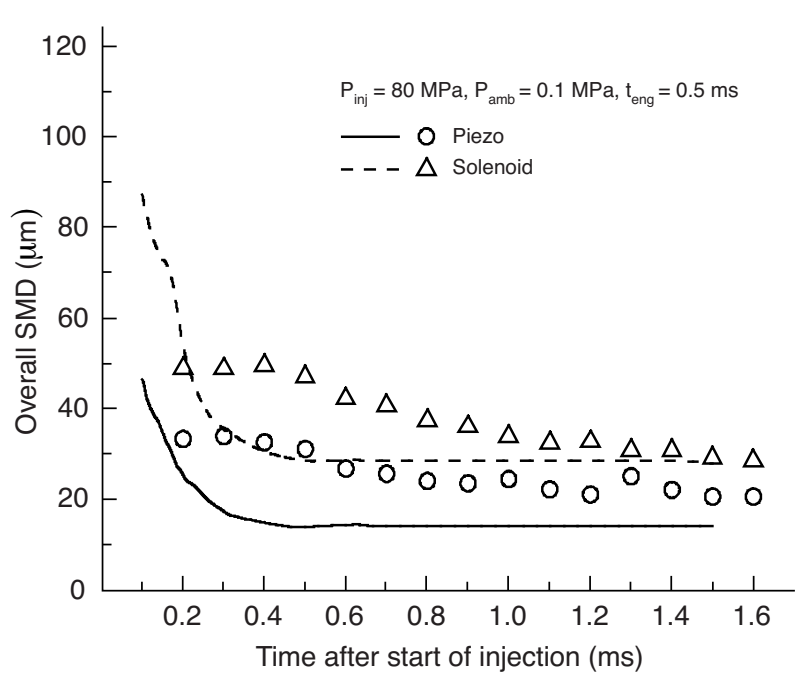

b

Figure 13

Overall SMD distributions of two injection systems. (a) $\theta=100^{\circ}$; (b) $\theta=150^{\circ}$. ( $\left.P_{\text {inj }}=80 \mathrm{MPa}, P_{\mathrm{amb}}=0.1 \mathrm{MPa}, t_{\mathrm{eng}}=0.5 \mathrm{~ms}\right)$.

system were detected before $4 \mathrm{~ms}$ of injection start; however, after $4 \mathrm{~ms}$ of injection start, the detected percentage of piezo injection system is smaller than solenoid injection system that showed almost constant value. It can be said that the wider spray injection angle induces the large spray area and the drag effect between fuel and ambient gas was increased at the initial injection time. As a result, the droplet detection may increase. Based on these results, it can be presumed that the outstanding injection performance of the piezo injection system promotes the droplet atomization.

Both experimental and calculated distributions of droplet mean velocities are illustrated in Figure 12. After showing its maximum value at the initial injection time, the mean velocity in both injectors gradually decreased with the elapsed time. This indicates that the spray internal structure dramatically changed near the nozzle tip where the atomization processes of droplets actively takes place at the initial injection time, and induced the rapid spray momentum loss.

Figure 13 shows the experimental and numerical results of the overall SMD distributions of both injection systems. The overall SMD of the piezo injection system was lower because the effective mean injection velocity of the piezo injector was higher than that of the solenoid injector and it could promote droplet atomization. As illustrated in the figures, the distributions of the predicted SMD reasonably agreed with the experiments in both the solenoid and piezo injector cases.

\section{CONCLUSIONS}

Based on the results of the experimental and numerical calculations of the spray and atomization characteristics for the piezo fuel injection system, the following conclusions can be drawn:

The injection profiles of the piezo injection system show that this injection system handles a large amount of injected fuel, has a short injection delay, and shows stabilization of the injection/energizing duration. Therefore, the piezo injection system performs well compare to the operating characteristics of the solenoid injection system.

The piezo injection system rapidly reached the peak injection rate and had uniform profiles as elapsed time after the start of injection. However, the solenoid injection system took more time to reach the peak injection rate than the piezo injection system. In contrast, the peak injection rates of the piezo and solenoid injection systems were similar since nozzles with the same specifications were installed.

The spray injected from the piezo injection system had a similar spray tip penetration to the solenoid injection system; however, the former had a large spray cone angle. It could be assumed that a large amount of injected fuel and rapid opening of the injector needle, due to the fast response of piezo injection system, caused the rapid increase of injection flow rate and enlarged the spray cone angle to about 10 degrees.

The comparison between the experimental and calculated results of spray tip penetration at atmospheric pressure showed that penetration was underestimated within $0.6 \mathrm{~ms}$ 
following the start of injection. It may be guessed that the high spray momentum caused by high injection pressure induced the rapid spray edges development at atmospheric condition. However, it showed good agreement as the ambient pressure increased to $3 \mathrm{MPa}$.

The microscopic atomization characteristics of the piezo injection system indicated that the outstanding injection performance of the piezo injector promoted droplet atomization. The calculated distributions of SMD reasonably agreed with the experimental results in both cases.

\section{ACKNOWLEDGEMENTS}

This work was supported by the CEFV (Center for Environmentally Friendly Vehicle) of the Eco-STAR project of the Ministry of the Environment (MOE) in Seoul, Republic of Korea. Also, this work is financially supported by the Ministry of Education and Human Resources Development (MOE), the Ministry of Commerce, Industry, and Energy (MOCIE), and the Ministry of Labor (MOLAB) through the fostering project of the Lab of Excellency.

\section{REFERENCES}

Arcoumanis C. (2000) Spray and Combustion Development in a Four-Valve Optical Di Diesel Engine, SAE Tech. Paper Series 2000-01-1183.

Bosch W. (1966) Fuel Rate Indicator Is a New Measuring Instrument for Display of the Characteristics of Individual Injection, SAE Tech. Paper Series 660749.

Fettes C., Leipertz A. (2001) Potentials of a Piezo-Driven Passenger Car Common-Rail System to Meet Future Emission LegislationsAn Evaluation By Means of In-Cylinder Analysis of Injection and Combustion, SAE Tech. Paper Series 2001-01-3499.

Ganser M. (1998) Common Rail Injector with Injection Rail Control, SAE Tech. Paper Series 981927.
Gupta S.E., Sekar R., Poola R. (2000) Effect of Injection Parameter on Diesel Spray Characteristics, SAE Tech. Paper Series 2000-01-1600.

Helmantel A., Gustavsson J., Denbratt I. (2005) Operation of a Di Diesel Engine with Variable Effective Compression Ratio in HCCI and Conventional Diesel Mode, SAE Tech. Paper Series 2005-01-0177.

Ibrahim E.A., Yang H.Q., Przekwas A.J. (1993) Modeling of Spray Droplets Deformation and Breakup, J. Propul. Power 9, 645-651.

Kim M.Y., Lee C.S. (2007) Effect of Narrow Fuel Spray Angle and Dual Injection Configuration on the Improvement of Exhaust Emission in a HCCI Diesel Engine, doi:10.1016/j:fuel 2007.03.016 (in Press).

Koyanagi K., Öing H., Renner G., Maly R. (1999) Optimizing Common-Rail Injection By Optical Diagnostics in a Transparent Production Type Diesel Engine, SAE Tech. Paper Series 1999-013646.

Lai M.C., Wang T.C., Xie X., Han J.S., Henein N., Schwarz E., Bryzik W. (1998) Microscopic Characterization of Diesel Sprays at VCO Nozzle Exit, SAE Tech. Paper Series 982542.

Park S.W., Lee C.S. (2003) Macroscopic Structure and Atomization Characteristics of High-Speed Diesel Spray, Int. J. Automotive Technol. 4, 157-164.

Reitz R.D. (1987) Modeling Atomization Processes in HighPressure Vaporizing Sprays, Atomization Spray Technol. 3, 309-337.

Sarre C.K., Kong S.C., Reitz R.D. (1999) Modeling the Effects of Injector Nozzle Geometry on Diesel Sprays, SAE Tech. Paper Series 1999-01-0912.

Tanaka T., Ando A., Ishizaka K. (2002) Study on Pilot Injection of DI Diesel Engine using Common-Rail Injection System, J. SAE 23, 297-302.

Taylor C., Washington G. (2003) The Application of Piezoceramic Actuation to Direct Fuel Injection, SAE Tech. Paper Series 200332-0001.

Timothy J.J., Stanislav V.B., Dennis N.A., Patrick G.S. (2005) Lean and Rich Premixed Compression Ignition Combustion in a LightDuty Diesel Engine, SAE Tech. Paper Series 2005-01-0166.

Final manuscript received in September 2007 